\title{
Killi Zeminlerin Kireç ile Stabilizasyonunun Deneysel Çalışması ve Sonuçların İstatistiksel Değerlendirilmesi
}

\author{
Mahmut Durmaz ${ }^{1 *}$ \\ 1*Siirt Üniversitesi, Mühendislik Fakültesi, İnşaat Mühendisliği Bölümü, Siirt, Türkiye (ORCID: 0000-0002-6060-4258)
}

(İlk Geliş Tarihi 25 Şubat 2020 ve Kabul Tarihi 13 Nisan 2020)

(DOI: 10.31590/ejosat.709160)

ATIF/REFERENCE: Durmaz, M. (2020). Killi Zeminlerin Kireç ile Stabilizasyonunun Deneysel Çalışması ve Sonuçların İstatistiksel Değerlendirilmesi. European Journal of Science and Technology, (18), 973-980.

\begin{abstract}
$\ddot{O} z$
$\mathrm{Bu}$ çalışmada ilk önce ince daneli zeminin özellikleri tayin edilmiş daha sonra da bu zemine farklı oranlarda kireç ilave edilerek oluşturulan malzemenin özellikleri araştıılmıştır. Bu amaçla ağırlıkça \%5, \%9 ve \%11 oranlarında 3 kireç-zemin karışımı numune hazırlanmıştır. Kireç ilavesinin kil numunelerin, kohezyon (c) ve içsel sürtünme açısı üzerine ( $\phi$, dolaylı olarak taşıma gücü) olan etkisi deneysel olarak incelenmiştir. Sonuçların doğruluğu SPSS istatistik analiz yazılımı yardımıyla tek yönlü varyans analizi kullanılarak kontrol edilmiştir. Üç eksenli basınç deney (UU) sonuçlarında; \%5 kireç katkısı için c=91.27 kPa ve $\phi=26,42$ derece, \%9 kireç katkısı için $\mathrm{c}=65.53 \mathrm{kPa}$ ve $\phi=29,43$ derece, $\% 11$ kireç katkısı için $\mathrm{c}=51.73 \mathrm{kPa}$ ve $\phi=31,81$ derece olarak bulunmuştur. Yapılan deney sonuçları daha önce bu konuda yapılan çalışmaların sonuçlarıyla aynı doğrultudadır. Kireç katkı miktarı arttıkça kohezyon azalmakta, iç sürtünme açısı ise artmaktadır. Yani taşıma gücü artmaktadır.
\end{abstract}

Anahtar Kelimeler: Kireç Stabilizasyonu; Zemin İyileştirilmesi, İnce Dane; Taşıma Gücü, Kil.

\section{Experimental Study of Lime Stabilization of Clay Soils and Statistical Evaluation of The Results}

\begin{abstract}
In this study, the properties of the fine-grained soil were determined firstly, and then, the properties of the material, which was created by adding lime with various proportions to this soil, were investigated. For this purpose, 3 lime-soil mixture samples were prepared in $5 \%, 9 \%$, and $11 \%$ by weight. The effect of lime addition to clay samples, cohesion (c), and internal friction angle ( $\phi$, to bearing capacity indirectly) was investigated experimentally. The accuracy of the results was checked by using one-way analysis of variance with the help of SPSS statistical analysis software. It was obtained from the unconsolidated-undrained (UU) triaxial testing that the lime addition for $5 \%, c=91.27 \mathrm{kPa}$ and $\phi=26,42^{\circ}$; for $9 \%, \mathrm{c}=65.53 \mathrm{kPa}$ and $\phi=29,43^{\circ}$; for $11 \%, \mathrm{c}=51.73 \mathrm{kPa}$ and $\phi=31,81^{\circ}$. The results of the experiments are in line with the results of previous studies. As the amount of lime addition increases, cohesion decreases and the internal friction angle increases. So the bearing capacity increases.
\end{abstract}

Keywords: Lime Stabilization; Soil Improvement, Fine-Grained; Bearing Capacity; Clay.

\section{Giriş}

Yapılarda kilin kireç ile stabilizasyonunun kullanımı 5000 yıldan daha eskidir. Tibet'teki Shersi piramitleri kil ve kirecin yoğunlaştırılmış karışımları kullanılarak inşa edilmiştir. Çin ve Hindistan tarihleri boyunca kireç stabilizasyonunu çeşitli şekillerde kullanmıştır. Bununla birlikte, zemin mekaniği laboratuvar testlerinin gelişen tekniklerinin zemin -kireç karışımlarını değerlendirmek için uygulaması 1940'ların sonuna doğru ABD'de gerçekleşmiştir. Killerin kireç ile işleme tabi tutulması 1950'lerde başlamış ve bu teknik hızla popülerlik kazanmıştır. ABD'nin binlerce millik otobanları ve Dallas Fort Worth gibi başlıca havalimanları kireç stabilizeli killer üzerine inşa edilmiştir. Stabilizasyon; Amerika Stabilizasyon Komitesi tarafindan "sağlamlık derecesi" veya malzemenin çeşitli maddeler katılarak düzeltilmesi" olarak tanımlanmaktadır (ARBA, 1971; Manual, 2004). Zemine kireç ve

\footnotetext{
* Sorumlu Yazar: Siirt Üniversitesi, Mühendislik Fakültesi, İnşaat Mühendisliği Bölümü, Siirt, Türkiye, ORCID:0000-0002-6060-4258 . e-posta: mahmutdurmaz@siirt.edu.tr
} 
çimento karıştırılmasının zemin özelliklerini iyileştirmede etkili olduğu bilinmektedir. Bu nedenle çok uzun süredir zemin stabilizasyonunda kireç ve çimento kullanılmaktadır. Özellikle karayolları ile hava meydanlarında kireç ve çimento stabilizasyonu başarı ile uygulanmaktadır (Kalava, 1992; Kavak ve ark., 2009).

Zemin stabilizasyonu ile zeminin plastisitesini azaltmak, geçirgenlik seviyesini ve sıkışabilirliğini en uygun hale getirmek ve mukavemetini maksimum seviyeye çıkarmak amaçlanmaktadır. Bu sayede zemin danelerinin arasındaki bağlar güçlendirilmektedir. Kireç katılarak stabilize edilen zemin tabakasının, plastisite indisinde artış veya azalma oluşmaktadır. (Çekil vd 2019).

Zeminlerin kireç ile iyileştirilmesi işleminde kimyasal ve fiziksel olmak üzere iki olay vardır. Kimyasal olaylar; iyon değişimi, çimentolaşma ve karbonatlaşma olarak üç farklı aşamada gerçekleşmektedir. Fiziksel olaylar ise flokülasyon, plastisite indisi ve hacim değişimi, maksimum kuru birim hacim ağıllıkta düşme ve optimum su muhtevasında artma, boşluk basıncı, don ve rutubet, mukavemet ile ilgili özelliklerdir.

Kireç ilave edilmesi ile oluşan puzolonik reaksiyonlar ve çimentolanma nedeni ile zeminin mukavemeti artmaktadır (Akyarlı vd. 2009). Katkı malzemeleri kullanıldığında kimyasal reaksiyonlar zamana bağlı olarak geliştiği için zeminin mukavemeti artacaktır. Sönmemiş kireç, sönmüş kirece göre daha fazla etkili ve daha fazla optimum rutubet yüzdesi verir (Kavak ve ark., 2008).

Yol çalışmaları sırasında, problemli zeminler söz konusu ise dört farklı çözüm önerisi bulunmaktadır. Bunlar;

1) Kötü özellikteki zeminin ortamdan uzaklaştırılması,

2) Yapı sisteminin doğal durumdaki zemin özelliklerine göre boyutlandırılması,

3) Yapı temelinin kötü zeminin aşă̆ısındaki sağlam tabakaya oturtulması

4) Zemin özelliklerinin istenilen yönde değiştirilmeye çalışılması olarak sıralanabilir

Bir malzemenin kusurlu yanlarını iyileştirmede uygulanacak maliyetin, bir başka maddeyle yer değiştirmesi maliyetinden daha az olması durumunda birçok doğal malzeme, yol inşaatında kullanılabilir duruma getirilmek için stabilize edilmektedir (Aksoy ve İskender, 2004).

Döşeme amaçlı olarak yol tabanlarının kireç ile stabilizasyonu geleneksel inşa yöntemlerine göre maliyet bakımından etkili bir alternatif olarak kabul görmüştür (Demir ve Kılıç, 2010). Kireç stabilizasyonundan faydalanılabilecek birçok mühendislik yapısı mevcuttur (Otoyol, ana ve tali yollar, geçit ve servis yolları, havalimanlarındaki pistler ve apronlar, araba park yerleri, fabrika alanları ve rampa stabilizasyonu, demiryolu rayları, yapısal dolgu).

Zeminlerin birçok önemli mühendislik özellikleri kireç işlemleri ile geliştirilmiştir. Genel olarak, kireç ile işleme tabi tutma ile zeminlerin;

- Mukavemet veya taşıma gücü kapasitesi artar.

- Zeminin sıkıştırıla bilirliğini azaltılarak yapıda şişme kabarma durumlarından dolayı oluşan zararlar minimize edilir (Öztürk ve ark., 2015).

- Zeminin geçirimliliğini azaltarak yer altı sularının akışı ve yer üstü suları tarafindan yapılan erozyon azaltılarak, başka yapı ve sıkıştırmalar için sağlam bir platform sağlanır.

Özellikle sönmemiş kireç ilavesi iri taneli zeminlerin geoteknik özellikleri üzerinde aşağıdaki etkilere sahiptir (Lime Stabilisation Manual, 1990):

- Nemin emilmesi, böylece zeminde nem içeriğinde azalmaya yol açılması, Optimum su içeriğinde artış,

- Proktor Optimumdaki yoğunlukta azalma

- Plastik limitinde artı̧

- Plastiklikte azalma

- Proktor sıkıştırması eğiminde dışa doğru yassılaşma

- California Dayanma Oranında (CBR) artış

- Bu etkilerin neredeyse hemen gerçekleşmesi

Daha uzun bir süreç içerisinde, puzolanik (çimentolaşma) tepkimeler gerçekleşir ve bu da aşağıdaki zemin özelliklerinin daha da gelişmesi ile sonuçlanır (Eroğlu ve ark., 2005).

- CBR'de daha fazla artış

- Serbest basınç mukavemetinde artış

- Makaslama mukavemetinde artış

- Çekme mukavemetinde artış

- Kabarma ve çekme karşısında gelişmiş sağlamlık 
- Donmaya karşı gelişmiş direnç

Kireç ürünleri ile zemin stabilizasyonu, elverişsiz veya marjinal zeminleri geçici veya kalıcı çalışmaların parçalarını oluşturmak için kolaylıkla yerleştirilebilen ve sıkıştırılabilen ve sıkışabilen kullanışlı yapı materyallerine dönüştürecektir (Soğancı ve Yıldız, 2011; Develioğlu, 2017).

Kireç stabilizasyonun çevresel faydaları büyük olabilir. Kireç, büyük miktarlarda elverişsiz materyalin kaldırılmasına ve eşit oranda büyük miktarlarda değişim dolgusunun yerine ithaline gerek bırakmaksızın yapı yerinde zemini stabilize etmektedir. Yol tabakalarının inşası için yığınlara gerek duyulmamakta, bu yüzden de madenden çıkarılan materyallere talep azalmaktadır. Yerel ve ulusal yollardaki trafik yükleri minimize edilmekte ve yerel topluluklarda yapı çalışmalarının etkisi önemli ölçüde indirgenmektedir (Vural, 2019; Akyarl1 ve ark., 2009).

Kireç stabilizasyonunda, kireç kil daneleriyle karıştırılarak hızlı bir reaksiyon oluşması sağlanır, bu şekilde plastisitesi çok yüksek olan killeri bile daha gevrek bir zemin haline getirir. Ayrıca kireç stabilizasyonu, yumuşak, dispersif killi zeminleri daha sıkı ve suya karşı dayanıklı bir malzeme haline getirir. Reaksiyonun hızından dolayı yöntem, özellikle yumuşak zeminleri daha dayanıklı hale getirmekte ve suya doygun siltlerde, hidratasyon için daha çok suya ihtiyaç duyan sönmemiş kireç kullanılarak, efektif iyileştirme sağlamaktadır. Kireç stabilizasyonu, tüm killi zeminlerin dayanımını, erozyona karşı direncini ve büzülme ile şişmeye karşı hacimsel stabilitesini artırır (Sarsılmaz, 2017).

Bell ve Tyrer (1989) tarafından yapılan araştırmada zeminin kimyasal ve minerolojik birleşiminin stabilizasyona etki ettiği düşünülmüştür. Üç ana kil mineralinden A, B, C gibi üç değişik numune türü oluşturmuş ve \%2, 3,4,6,8 kireç ve çimento karışımları hazırlanıp bunlar üzerinde deneyler yapmışlardır. Kalava (1992), zeminin kireç ve çimento ile stabilizasyonuna ait bir çalışma yapmıştır. Stabilize malzeme üretilmesinde, kireç için ağırlıkça \%1, \%2, \%3, \%4, \%6, \%8, \%10, \%15; çimento için ağırlıç̧a \%4, \%6, $\% 7, \% 8, \% 10, \% 12,5, \% 15, \% 20$ karışımları hazırlanmıştır. Türköz (2006), çalışmasında sönmüş kireç katk1 yüzdelerini (\%0, \%1, \%3 ve \%5) hazırlanmış ve yaptığı deneyler sonunda, sönmüş kireç katkısının killerin şişme potansiyelinin kontrolünde başarıyla kullanılabileceği, bu katkının \%3 seviyesinden sonra etkili olduğu ve etkinin yüksek enerji seviyesinde nispi olarak daha yüksek görüldüğü belirlemiştir. Dhar ve Hussain (2019), çalışmalarında farklı kireç yüzdelerinin (\%3, \%5, \%7 ve \%9) kireç alt zemin toprağının mukavemet ve taşıma kapasitesi iyileştirme yönelik araştırma yapmışlardır. Yapılan literatür taraması sonucunda çalışmamızda kireç oranların $\% 0, \% 5, \% 9, \% 11$ seçilmiştir.

\section{Materyal ve Yöntem}

Bu çalışmada; TS 1900-1'e göre Proctor deneyi yapılarak numunenin doğal birim hacim ağırlığı(yoğunluk) ve numunenin doğal optimum su içeriği, \%5, \%9, \%11 kireç katkılı killi zemin numunelerinin de ayrıca birim hacim ağırlıkları ve optimum su içerikleri bulunmuştur. TS 1900-2/T1 standardı ile doğal killi zemin, \%5, \%9, \%11 kireç katkılı killi zemin numunelerinin üç eksenli sıkışma deneyi ile (UU) deneyi yapılmıştır. TS 1900-1 Zeminlerin Kıvam (Atterberg) limitleri tayini likit limit (LL), plastik limit (PL), plastisite indeksi (PI) bulunmuştur.

Ayrıca kil, Karayolları Genel Müdürlüğünün Zayıf Zemin Stabilizatörleri Teknik Şartnamesi 2005'göre iyileştirilmesi düşünülen kil sınıfında yer almakta ve arazi koşullarında temin edilerek (TS EN 459-2) uygun kireç katkı malzemesi, Karayolları Genel Müdürlügüünün Kireç Stabilizasyonu Teknik Şartnamesi 2005 `e göre katılarak deneysel çalışmalar gerçekleştirilmiştir. Bu çalışma kapsamında arazi koşullarında temin edilen kil zemin ve kireç katkı malzemesi kullanılarak amaçlanan çalışmalar gerçekleştirilmiştir.

\subsection{Kil}

AASHTO veya Birleştirilmiş Zemin Sınıflandırma Sistemine göre A5, A6, A7, A-2-6, A-2-7 veya CH, CL, MH, ML, GC, SC sınıflarına giren, plastisite indeksi 10'dan büyük (PI > 10) olan veya Kaliforniya Taşıma Oranı (Yaş CBR \% ) < 10 veya CBR şişme \% si > 3 olan topraklar için stabilizasyon-iyileştirme düşünülmelidir (Zayıf Zemin Stabilizatörleri Teknik Şartnamesi 2005). Bu çalışmada kullanılan kil iyileştirilme düşünülen zemin sınıfında yer almaktadır.

\subsection{Su}

Toprak-su karışımı için karıştırma işlemini ideal nem koşullarında yapmak, sıkıştırma ve sıkıştırma sonrasında toprak-su-kireç reaksiyonunun devamı için kullanılacak su tatlı, berrak olmalı, içerisinde kirlilik oluşturacak nitelikte (yağ, asit, alkali madde, klorür, sülfat ve organik madde) madde bulunmamalıdır. Sülfat miktarı $\mathrm{S}_{3}<200$ ppm olmalıdır (Kavak vd. 2008).

\subsection{Kireç}

Stabilizasyon-iyileştirme işleminde kullanılacak kireç özellikleri (TS EN 459-2) Tablo l'de verilen özelliklere sahip olmalıdır. Bu çalışmada kullanılan kireç Tablo 1'de sunulan özelliklere uygun olarak seçilmiştir. 
Tablo 1. Stabilizasyon işleminde kullanılacak kirecin kimyasal ve fiziksel özellikleri

\begin{tabular}{|c|c|c|}
\hline Özellik (TS EN 459-2) & Sönmemiş Kireç & Sönmüş Kireç \\
\hline $\mathrm{CO}_{2}(\mathrm{Klzd}$ lrma Kaybl) & $<7 \%$ & $<7 \%$ \\
\hline Toplam $(\mathrm{CaO}+\mathrm{MgO})$ & $>80 \%$ & $>80 \%$ \\
\hline $\mathrm{SO}_{3}$ & $<2 \%$ & $<2 \%$ \\
\hline $\mathrm{MgO}$ & $<10 \%$ & $<10 \%$ \\
\hline $\mathrm{SiO}_{2}+\mathrm{Al}_{2} \mathrm{O}_{3}+\mathrm{Fe}_{2} \mathrm{O}_{3}+\mathrm{SO}_{3}$ & $<5 \%$ & $<5 \%$ \\
\hline Parçalar & $<2 \mathrm{~mm}$ & - \\
\hline A ğırlıkça elekte kalan \% & - & $\begin{array}{c}0.09 \mathrm{~mm}<\% 70.2 \mathrm{~mm} \\
<\% 2\end{array}$ \\
\hline
\end{tabular}

Kirecin sönmesi esnasında ağırlıkça \%30 mertebesinde suyu bünyesine alma özelliği vardır. Bu özellik göz önüne alınarak doğal su içeriğinin optimum su içeriğinden çok yüksek olduğu durumlarda sönmemiş kireç tercih edilebilir (Kireç Stabilizasyonu Teknik Şartnamesi; 2005).

\subsection{Deneysel Çalışmalar}

Araziden alınan zemin numunelerinin öncelikle zemin özellikleri belirlenmiş ve zeminin (CH-) yüksek kapasiteli killi zemin olduğu tespit edilmiştir. Deneysel çalışmalarda kullanılan kil zemin numunesinin Casagrande Plastisite Kartındaki konumu Şekil 1'de gösterilmiştir.

Zemin özellikleri belirlenen kil numunesine ağırlıça \%5, \%9, \%11 kireç ilave edilmesiyle elde edilen numuneler üç eksenli basınç deneyine tabi tutulmuş ve yapılan hesaplamalar neticesinde kohezyon (c) ve sürtünme açısı $(\phi)$ değerleri tespit edilerek deneyler sonlandırılmıştır.

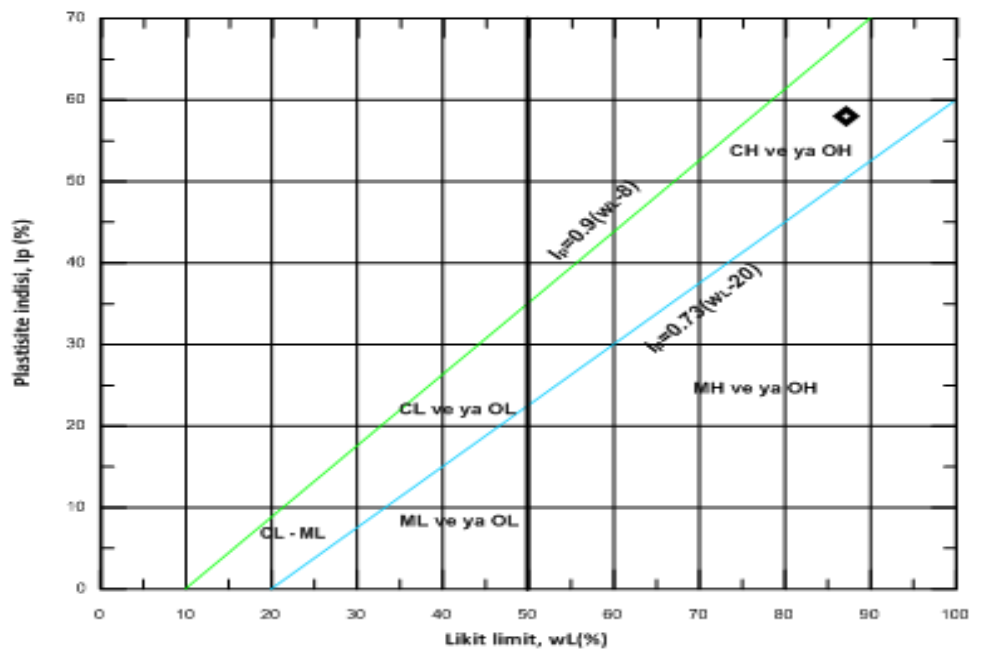

Şekil 1. Çalışmada kullanılan zeminin Casagrande Plastisite Kartındaki konumu

Her bir kireç katkı oranında hazırlanan numunelerle üç eksenli basınç deneyleri yapılmış ve elde edilen c ve $\phi$ değerleri Tablo 2'de gösterilmiştir.

Tablo 2. Üç eksenli $(U-U)$ basınç deneylerinden elde edilen c ve $\phi$ değgerleri

\begin{tabular}{cccccccccc}
\hline N.No & \multicolumn{2}{c}{ Doğal Numune } & \multicolumn{2}{c}{ \%5 Kireç } & \multicolumn{2}{c}{ \%9 Kireç } & \multicolumn{2}{c}{ \%11 Kireç } \\
\hline & $\mathrm{c}$ & $\phi$ & $\mathrm{c}$ & $\phi$ & $\mathrm{c}$ & $\phi$ & $\mathrm{c}$ & $\phi$ \\
1 & 31.59 & 7.85 & 89.37 & 25.11 & 63.50 & 28.47 & 49.90 & 30.91 \\
2 & 33.48 & 9.15 & 92.59 & 27.40 & 67.60 & 30.45 & 53.60 & 32.57 \\
3 & 32.41 & 8.49 & 91.86 & 26.76 & 65.48 & 29.36 & 51.69 & 31.96 \\
\hline
\end{tabular}

Not: $\mathrm{c}=$ iç kohezyon, $\phi=$ iç sürtünme açısı

Yapılan üç eksenli basınç deneyleri sonucunda elde edilen c ve $\phi$ değerlerinin değişimi sırasıyla Şekil 2 ve Şekil 3 ’te sunulmuştur. 
Avrupa Bilim ve Teknoloji Dergisi

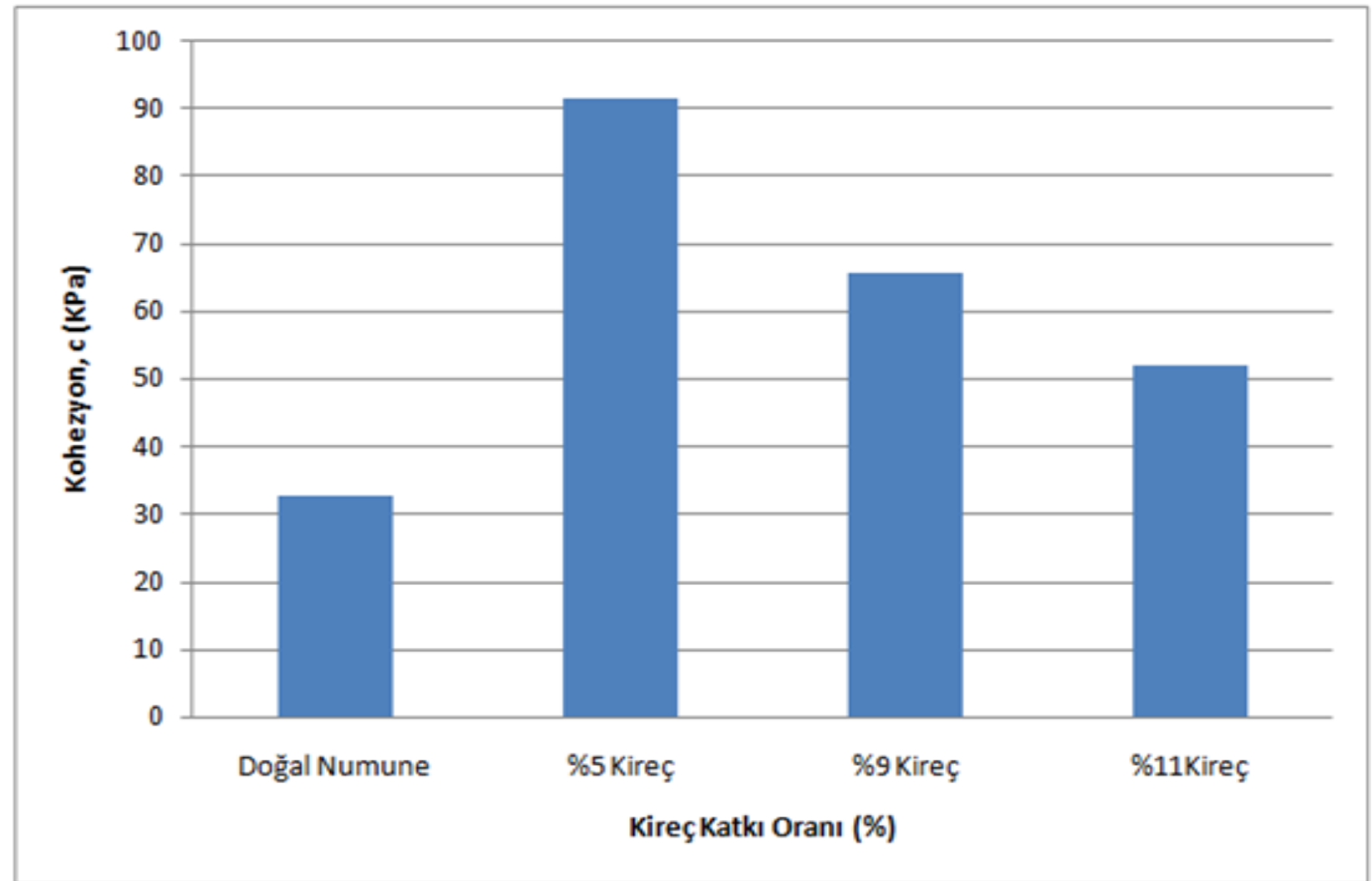

Şekil 2. Kireç katkı oranına bağlı olarak c değerlerinin değişimi

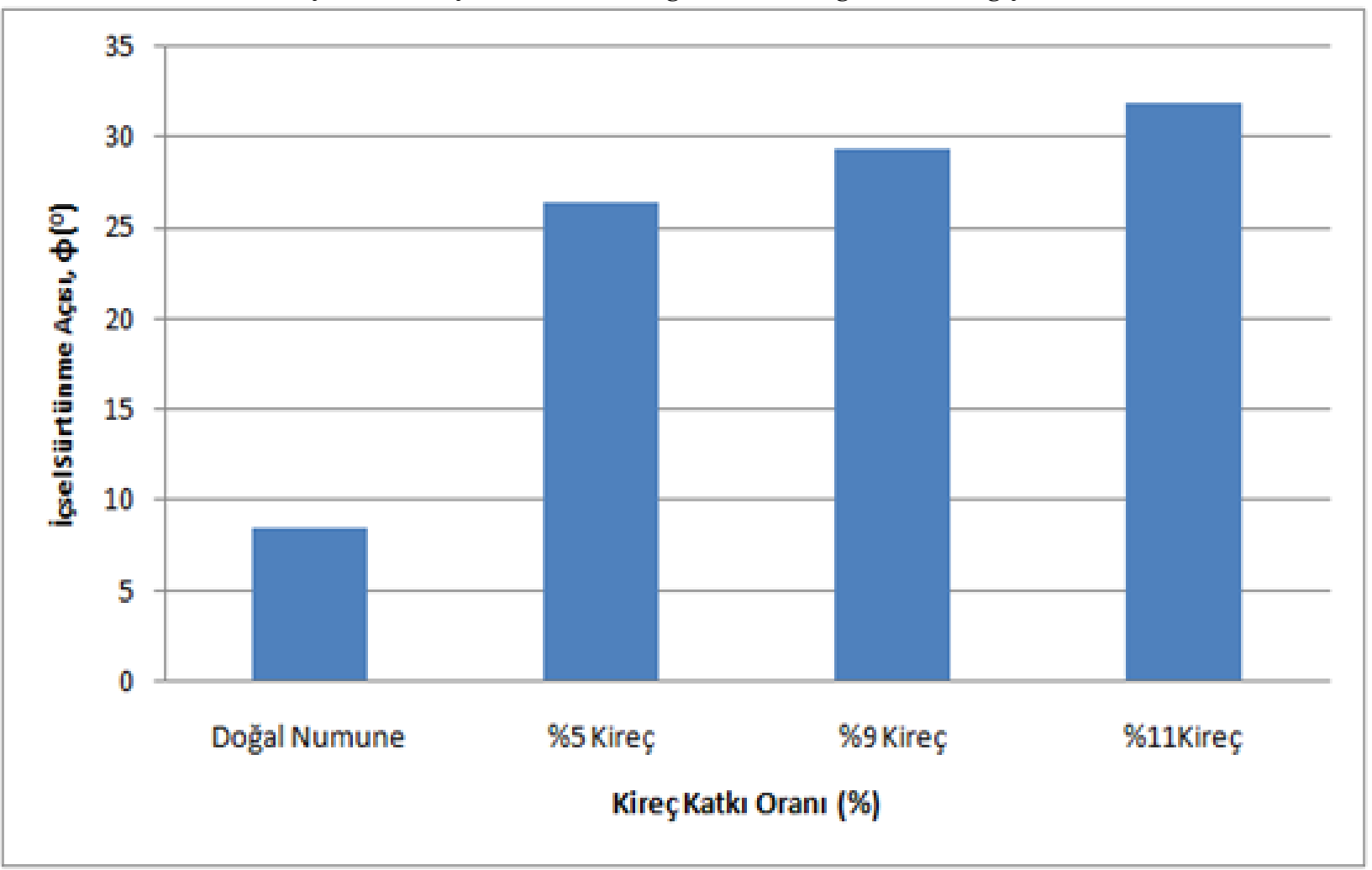

Şekil 3. Kireç katkı oranına bă̆glı olarak $\phi$ değerlerinin değişimi

Yapılan deney sonuçları Tablo 3'te sunulmuştur. 
Tablo 3. Deneysel çalışmalar sonucunda elde edilen veriler

\begin{tabular}{ccccc}
\hline & Doğal Numune & \%5 Kireç & \%9 Kireç & \%11 Kireç \\
\hline$W_{n}$ & 40.30 & - & - & - \\
$\gamma_{n}$ & 17.66 & - & - & - \\
$L L$ & 87 & - & - & - \\
$P L$ & 29 & - & - & - \\
$P I$ & 58 & - & - & - \\
$W o p t(\%)$ & - & 28.20 & 28.80 & 28.10 \\
$\gamma_{d}\left(\mathrm{kNm}^{3-1}\right)$ & - & 1.37 & 1.34 & 1.33 \\
$\gamma_{n}\left(\mathrm{kNm}^{3-1}\right)$ & - & 1.76 & 1.72 & 1.70
\end{tabular}

Kısaltmalar: $\mathrm{W}_{\mathrm{n}}$ : Doğal su muhtevası, $\gamma_{\mathrm{n}}$ : Doğal yoğunluk, LL: Likit limit, PL: Plastik limit, PI: Plastisite indeksi, $\mathrm{W}_{\text {opt }}$ : Optimum su içeriği, $\gamma_{\mathrm{d}}$ : Katkısız numune max. kuru birim ağırlı̆̆ ${ } \gamma_{\mathrm{n}}\left(\mathrm{kNm}^{3-1}\right):$ Kireçli numune max. Kuru birim ağırlığı

Çeşitli oranlarda kireç katılarak hazırlanmış numuneler üzerinde yapılan deneyler sonucunda; toplam gerilme $(\sigma)$ - kayma gerilmesi $(\tau)$ eğrilerinin birbirlerine benzerlik gösterdiği görülmüştür.

\section{5. İstatistik Analiz}

Çeşitli yüzdelerde katılan kireç ile zemin stabilizasyonu arasındaki ilişkiyi belirlemek için hazırlanan aynı zemin için hazırlanan üç zemin numunesinin her birinin içsel sürtünme açısı ve kohezyonu hesaplanmıştır. Numunelere daha sonra $\% 5, \% 9$ ve $\% 11$ kireç yüzdelerine ulaşılana kadar kireç eklenmiş ve yukarıda bahsedilen ölçümler tekrarlanmıştır. Her bir ölçüm sonucu Çizelge 2 'te sunulmuştur.Tablo 2'de sunulan ölçümlere dair betimsel istatistikler Şekil 2 ve Şekil 3'te görselleştirilmiş, Tablo 4 'te özetlenmiş̧ir. Ayrıca gerçekleştirilen iki tane tek yönlü ANOVA (Varyans Analizi) ile iç kohezyon (c) ve kayma açısı ( $\phi$ ) ortalamalarının ile her bir kireç karışım yüzdesinde istatistiksel olarak birbirinden farklılaşıp farklılaşmadığı tespit edilmiştir. ANOVA sonuçları anlamlı bir farklılığ 1 işaret ettiğinde ikili karşılaştırmalarla farklılıkların hangi kireç karışım yüzdeleri arasında olduğu belirlenmiştir. Böylelikle en üst seviyede zemin stabilizasyonu sağlaması ön görülen kireç karışım yüzdesine ilişkin önerilerde bulunulmuştur.

Tablo 4. Çeşitli kireç yüzdelerinde yapılan zemin stabilizasyonu ölçümü betimsel istatistikleri

\begin{tabular}{ccccc}
\hline Kireç & \multicolumn{2}{c}{$\mathbf{c ~ ( k P a )}$} & \multicolumn{2}{c}{$\boldsymbol{\phi}\left(^{\circ}\right)$} \\
\hline & Ortalama & Standart Sapma & Ortalama & Standart Sapma \\
\hline $\begin{array}{c}\text { Doğal Numune }(\% 0 \\
\text { Kireç) } \\
\text { \%5 Kireç }\end{array}$ & 32.49 & 0.95 & 8.50 & 0.65 \\
\%9 Kireç & 91.27 & 1.69 & 26.42 & 1.18 \\
\%11 Kireç & 65.53 & 2.05 & 29.43 & 0.99 \\
\hline
\end{tabular}

Not: $\mathrm{c}=$ iç kohezyon, $\phi=$ iç sürtünme açısı, Numune sayısı=3

İç kohezyon ile kireç karışım yüzdesi arasındaki ilişkiyi belirlemek için $\alpha=.05$ seviyesinde iç kohezyon değerinin bağımlı değişken olduğu, kireç karışım yüzdesinin bağımsız - tekrarlayan değişsen olduğu bir yönlü gruplar içi ANOVA gerçekleştirilmiştir. Kireç karışım yüzdesi ile iç kohezyon değeri arasında anlamlı ilişki bulunmuştur ( $F(3.6)=5933.11, p<.0001, \eta 2=.996)$ Sonrasında her bir kireç karışım yüzdesinde ölçülen ortalama iç kohezyon değerleri ikili olarak karşılaşıtırılmış, aile boyu I. tip hata miktarı Bonferroni düzeltmesi ile $\alpha=.05$ seviyesinde sabit tutulmuştur. Her bir ikili karşılaştırma sonucunda ortalama iç kohezyon değerleri arasında anlamlı farklılık bulunmuştur, farklılıklar Tablo 5'te özetlenmiştir. Tablo 5'teki sonuçlara göre herhangi iki kireç karışım yüzdesine dair ortalama iç kohezyon seviyeleri, anlamlı farklılık göstermektedir. 
Tablo 5. Farklı yüzdelerde kireç içeren zeminlere ait c değerleri arasında ikili karşılaştırma sonuçları

\begin{tabular}{ccccc}
\hline Farklı1.k & Kestirim & Serbestlik Derecesi & $\mathrm{t}$ & $\mathrm{p}$ \\
\hline \%11 Kireç- \%9 Kireç & -13.797 & 2 & -119.433 & $.0004^{* * *}$ \\
\%11 Kireç- \%5 Kireç & -39.543 & 2 & -115.420 & $.0005^{* * *}$ \\
\%11 Kireç- \%0 Kireç & 19.237 & 2 & 36.785 & $.0044 * *$ \\
\%9 Kireç- \%5 Kireç & 25.746 & 2 & 63.42 & $.0015^{* *}$ \\
\%9 Kireç- \%0 Kireç & 33.033 & 2 & 51.757 & $.0022^{* *}$ \\
\%5 Kireç- \%0 Kireç & 58.780 & 2 & 115.358 & $.0005^{* * *}$ \\
\hline
\end{tabular}

Not: $* \mathrm{p}<.05, * * \mathrm{p}<.01, * * * \mathrm{p}<.001$. Bonferroni düzeltmesi ile aile boyu I. tip hata miktarı $\alpha=.05$ seviyesinde sabit tutulmuştur.

İçsel sürtünme açısı ile kireç karışım yüzdesi arasındaki ilişkiyi belirlemek için $\alpha=.05$ seviyesinde içsel sürtünme açısının bağımlı değişken olduğu, kireç karışım yüzdesinin bağımsız - tekrarlayan değişken olduğu bir yönlü gruplar içi ANOVA gerçekleştirilmiştir. İç sürtünme açısı ile kireç karışım yüzdesi arasında anlamlı ilişki bulunmuştur $(F(3,6)=4845.81, p<.0001, \eta 2=.993)$. Sonrasında her bir kireç karışım yüzdesinde ölçülen ortalama iç sürtünme açısı değerleri ikili olarak karşılaştırılmış, aile boyu I. tip hata miktarı Bonferroni düzeltmesi ile $\alpha=.05$ seviyesinde sabit tutulmuştur. Söz konusu ikili karş1laştırmalara ait sonuçlar Tablo 6'da sunulmuştur. Tablo 6'daki sonuçlara göre herhangi iki kireç karışım yüzdesine dair ortalama iç sürtünme açıları anlamlı farklılık göstermektedir.

Tablo 6. Farklı yüzdelerde kireç içeren zeminlere ait $\phi$ değerleri arasında ikili karşılaştırma sonuçları

\begin{tabular}{ccccc}
\hline Farklılı & Kestirim & $\begin{array}{c}\text { Serbestlik } \\
\text { Derecesi }\end{array}$ & t & p \\
\hline \%11 Kireç- \%9 Kireç & 2.386 & 2 & 16.914 & $.0209 *$ \\
\%11 Kireç- \%5 Kireç & 5.390 & 2 & 26.269 & $.0087 * *$ \\
\%11 Kireç- \%0 Kireç & 23.317 & 2 & 180.550 & $.0002^{* * *}$ \\
\%9 Kireç- \%5 Kireç & 3.003 & 2 & 13.613 & $.0321^{*}$ \\
\%9 Kireç- \%0 Kireç & 20.930 & 2 & 105.399 & $.0005 * * *$ \\
\%5 Kireç- \%0 Kireç & 17.927 & 2 & 53.772 & $.0021^{* *}$ \\
\hline
\end{tabular}

Not: ${ }^{*} \mathrm{p}<.05, * * \mathrm{p}<.01, * * * \mathrm{p}<.001$ Bonferroni düzeltmesi ile aile boyu I. tip hata miktarı $\alpha=.05$ seviyesinde sabit tutulmuştur

\section{Bulgular ve Tartışma}

Yapılan üç eksenli basınç deneyleri ile kireç katkı oranına bağlı olarak iç kohezyon ve iç sürtünme değerlerinde çok belirgin bir farklılık gözlemlenmiştir. Kireç katkı oranı arttıkça hem kohezyon hem de iç sürtünme açısı kireçsiz doğal numuneye göre daha fazladır. Ancak iç kohezyon, \%5'lik kireç içeren numunelerde en üst seviyeye çıkıp, kireç katkı oranının daha da artmasıyla düşüş göstermektedir. Başlangıçta kohezyonlu bir zemin davranış gösteren zemin numunesi katkı oranına bağlı olarak iri daneli zemin davranışı göstermiştir. Kireç katkısı zemin içinde çimentolaşma özelliği göstermiştir. Ayrıca çalışmada incelenen kireç katkı yüzdeleri göz önüne alındığında, kireç katkı yüzdesindeki artış, iç sürtünme açısındaki artışla açıkça ilişkilidir. Böylece \%11 $\phi$ (iç sürtünme açısı) kadar artamaya devam etmektedir. Yani taşıma gücü \%5 optimum seviyeye kadar artmaktadır ve sonra kohezyonun düşmesiyle azalmaktadir.

Yapılan deney sonuçlarını desteklemek amacıyla SPSS istatistik paket programıla tek yönlü varyans analizi Anova uygulanmıştır. Tablo 5'de kohezyon (c) ve Tablo 6 'da bulunan iç sürtünme açısı $(\phi)$ arasında ikili karşılaştırmalar yapılmış ve her bir ikili karşılaştırma sonucunda ortalama iç kohezyon değerleri (c) için (F $(3.6)=5933.11$, p <.0001, $\eta 2=.996)$ olduğundan ve içi sürtünme açıları $(\phi)$ için $(\mathrm{F}(3,6)=4845.81, \mathrm{p}<.0001, \eta 2=.993)$ olduğundan; anlamlı farklılık bulunmuştur. Değerlerin arasında anlamlı etki olması, zemine yapılan kireç katkısının zemini iyileştirdiğini dolayısıyla teorimizi ve deneysel çalışmamızı istatistik yöntemle destekler niteliktedir.

$\mathrm{Bu}$ çalışmada Siirt ili çevresinde HES bölgesinden alınan stabilizasyona uygun killi zemin üzerinde çalışma yapılmış, yol tabanını oluşturan zeminin güçlendirilmesi ile daha sağlam bir yol temeli oluşturulacağı ve daha uzun kullanılan bir karayolu olmakla birlikte kireç ile stabilizasyon klasik iyileştirme yöntemlerine göre \%40 daha ekonomik olmaktadır.

Bu çalışma sonrasında çeşitli sert kabuklu yemişlerin (biokütle) ısınma amacıyla vb. yakılmasından sonra elde edilen atık küllerin kimyasal analizleri sonucunda içinde \%10'dan fazla CaO'ya sahip olan küller, ASTM C618 içindeki yüksek kireçli uçucu kül grubuna girmektedir. Kireç oranı fazla olan biokütle küllerinin zemin stabilizasyonunda kullanılması başarılı sonuçlar verebilir. 


\section{Sonuç}

Deney sonuçlarında; $\% 5$ kireç katkısı için $\mathrm{c}=91.27 \mathrm{kNm} 2-1$ ve $\phi=26^{\circ} .42 ; \% 9$ kireç katkısı için $\mathrm{c}=65.53 \mathrm{kNm} 2^{-1}$ ve $\phi=29.43^{\circ}$; $\% 11$ kireç katkısı için $\mathrm{c}=51.73 \mathrm{kNm}^{-1}$ ve $\phi=31.81^{\circ}$ olarak hesaplanmıştır. Yapılan deney sonuçları incelendiğinde daha önce bu konuda yapılan çalışmalarla aynı doğrultudadır. Kireç katkı miktarına bağlı olarak $\gamma$ (birim hacim ağırlık) ile c değeri azalmakta, $\phi$ (iç sürtünme açısı) ise katkı oranına bağlı olarak artmaktadır. Kireç katkısı \% kaç olursa olsun $(\% 5, \% 9, \% 11$ için yapılan çalışma dahilinde), zemin özellikleri doğal zeminden daha iyi olmaktadır.

\section{Teșekkür}

Bu çalı̧̧mada beni destekleyen Prof. Dr. M. Haluk Çelik, Dr. Öğr. Üyesi Sungur Gürel ve Arş. Gör. Murat Gülen’e teşekkür ederim.

\section{Kaynakça}

Aksoy, A., İskender, E., 2004 Şubat. Yol Yapılarında Çimento ve Kireç Stabilizasyonu, Yapı Dünyası Dergisi, 54-60.

Akyarlı, A., Kavak, A., Atay, S., \& Alkaya, S., 2009. Killi Zeminlerin Kireç ile İyileştirilmesi. TSE Standart Dergisi, 566, 108-112.

ARBA- American Road Builders Assocation Stabilization Committee, 1971. Materials for Stabilization, HC-100,1-1, 7-10

Bell, F. G., and Tyrer, M. J., 1989. The Enhancement of The Properties of Clay Soils by The Addition of Cement or Lime. Proceedings of the 12th International Conference on Soil Mechanics and Foundation Engineering, 1339-1341.

Demir, S. ve Kılıç M., 2010. Şişen Zeminlerin Tanımlanması ve Zemin. Gaziosmanpaşa Üniversitesi Ziraat Fakültesi Dergisi, 27(1), 95-104.

Develioğlu, İ., 2017. İzmir Körfezi Organik Zeminlerinin Geoteknik Karekterizasyonu ve Sıkışabilirlik Davranışları ve Stabilizasyon İçin Çözüm Önerileri, Yüksek lisans Tezi, İzmir Kâtip Çelebi Üniversitesi Fen Bilimleri Enstitüsü, İzmir.

Dhar, S., \& Hussain, M. (2019). The strength and microstructural behavior of lime stabilized subgrade soil in road construction. International Journal of Geotechnical Engineering, 1-13.

Eroğlu, H., İmamoğlu, S. ve Acar, H. H., 2005. Kraft Kâğıt Hamuru Fabrikası Kimyasal Geri Kazanma Ünitesinde Oluşan Anorganik Atığın (Kireç Çamuru) Orman Yolu Stabilizasyonunda Değerlendirilmesi., Kafkas Üniversitesi Artvin Orman Fakültesi Dergisi, 6(1), 146-154.

Kalava, İ., 1992. Killerin Çimento ve Kireç ile Stabilizasyonu, Yüksek Lisans Tezi, Anadolu Üniversitesi Fen Bilimleri Enstitüsü İnşaat Müh. Anabilim Dalı, Eskişehir.

Kavak, A., Gürkan Güngör, A., Avşar, C. ve Atbaş, B., 16-17 Ekim 2008. Kireç ile Zemin Stabilizasyonu, Zemin Mekaniği ve Temel Mühendisliği On ikinci Ulusal Kongresi, Selçuk Üniversitesi, Konya.

Kavak, A., Güngör, A. G., Avşar, C., Yönter, G., Tokgöz, M., ve Akyarlı, A. (2009) Kil Oranı Yüksek Bir Dolgu Malzemesinin Kireç ile Stabilizasyonu. 14. Ulusal Kil Sempozyumu, KTÜ, Trabzon.

Kireç Stabilizasyonu Teknik Şartnamesi, 2005. Mart, Karayolları Genel Müdürlüğü, Tek.Ar.D.Bşk.lığı, Üstyapı Şb. Müdürlüğü,

Manual, C. (2004). Lime-Treated Soıl Construction Manual Lime Stabılizatıon \& Lime Modıfication. published by National Lime Association, USA, Bulletin, 326.

Öztürk, Y. Z., Ünsal, N. ve Akbaş, S. O., 2015. Gölbaşı Ankara Yerleşim Alanını Killerinin Şişme ve Kireç ile İyileştirilme Potansiyellerinin Belirlenmesi., Gazi Üniversitesi Mühendislik-Mimarlık Fakültesi Dergisi, 30(2). 309-318.

Sarsılmaz, O.M., 2017. Zemin İyileştirme Yöntemlerinin Sınıflandırılması, İncelenmesi, Değerlendirilmesi ve Anılan Yöntemlerin Seçilme Kriterleri Üzerine Kapsamlı Bir Araştırma, Yüksek lisans Tezi, Ege Üniversitesi Fen Bilimleri Enstitüsü, İzmir.

Soğancı, A. S. ve Yıldız, M., 2011. Tekrarlı Donma ve Çözülmenin Kireç ile Stabilize Edilmiş Kil Zeminlerin Mukavemet ve Permeabilitesine Etkisi. Selçuk-Teknik Dergisi, 10(3), 259-270.

Türköz, M., 2006. Şişen Killerin Kireç Katkısı ile Stabilizasyonu ve Eskişehir-Meşelik Killerine Uygulanması. Eskişehir Osmangazi Üniversitesi Mühendislik ve Mimarlık Fakültesi Dergisi, 19(2), 75-88.

Vural, İ., 2019. Utilization of Construction Demolition Waste in Soil Improvement. Academic Platform Journal of Engineering and Science, 7(1), 1-6.

Zayıf Zemin Stabilizatörleri Teknik Şartnamesi, 2005. Mart, Karayolları Genel Md.lüğü, Tek.Ar.D.Bşk.lığı, Üstyapı Şb.Md.lüğü, 